\title{
The role of the disulfide bond in the interaction of islet amyloid polypeptide with membranes
}

\author{
Lucie Khemtémourian • Maarten F. M. Engel • \\ John A. W. Kruijtzer · Jo W. M. Höppener · \\ Rob M. J. Liskamp · J. Antoinette Killian
}

Received: 11 September 2009/Revised: 3 December 2009/Accepted: 14 December 2009/Published online: 6 January 2010

(C) The Author(s) 2010. This article is published with open access at Springerlink.com

\begin{abstract}
Human islet amyloid polypeptide (hIAPP) forms amyloid fibrils in pancreatic islets of patients with type 2 diabetes mellitus. It has been suggested that the $\mathrm{N}$-terminal part, which contains a conserved intramolecular disulfide bond between residues 2 and 7, interacts with membranes, ultimately leading to membrane damage and $\beta$-cell death. Here, we used variants of the hIAPP ${ }_{1-19}$ fragment and model membranes of phosphatidylcholine and phosphatidylserine $(7: 3$, molar ratio) to examine the role of this disulfide in membrane interactions. We found that the disulfide bond has a minor effect on membrane insertion properties and peptide conformational behavior,
\end{abstract}

L. Khemtémourian $(\bowtie) \cdot$ M. F. M. Engel · J. A. Killian Chemical Biology and Organic Chemistry,

Institute of Biomembranes, Utrecht University, Padualaan 8, $3584 \mathrm{CH}$ Utrecht, The Netherlands

e-mail: 1.p.khemtemourian@uu.nl

M. F. M. Engel · J. W. M. Höppener

Department of Metabolic and Endocrine Diseases,

Division of Biomedical Genetics, University Medical Center

Utrecht, Utrecht, The Netherlands

J. A. W. Kruijtzer · R. M. J. Liskamp

Medicinal Chemistry and Chemical Biology, Utrecht University,

Sorbonnelaan 16, 3584 CA Utrecht, The Netherlands

J. W. M. Höppener

Netherlands Metabolomics Center, University Medical Center

Utrecht, P.O. Box 85090, 3508 AB Utrecht, The Netherlands

Present Address:

M. F. M. Engel

Astbury Centre for Structural Molecular Biology,

Institute of Molecular and Cellular Biology,

University of Leeds, Leeds LS2 9JT, UK as studied by monolayer techniques, ${ }^{2} \mathrm{H}$ NMR, ThT-fluorescence, membrane leakage, and $\mathrm{CD}$ spectroscopy. The results suggest that the disulfide bond does not play a significant role in hIAPP-membrane interactions. Hence, the fact that this bond is conserved is most likely related exclusively to the biological activity of IAPP as a hormone.

Keywords Amylin · Protein-membrane interactions . Model membranes $\cdot{ }^{2} \mathrm{H}$ NMR $\cdot$ Circular dichroism . Type II diabetes mellitus

\section{Introduction}

Type 2 diabetes mellitus (DM2) is characterized histopathologically by the presence of fibrillar amyloid deposits in the pancreatic islets of Langerhans (islet amyloid). The main component of these amyloid fibrils is the 37-aminoacid residue human islet amyloid polypeptide (hIAPP), a hormone that is normally co-secreted with insulin by the $\beta$-cells of the pancreas (Westermark et al. 1987). Although the normal physiological role of hIAPP is not entirely clear, it has been shown that the peptide plays a role as a hormone in suppression of gastric emptying, food intake, and glucose homeostasis (Akesson et al. 2003; Reda et al. 2002; Rushing et al. 2001).

It is thought that hIAPP amyloid formation is cytotoxic to the islet $\beta$-cells (Höppener et al. 2000; Khemtémourian et al. 2008), and that this cytotoxicity involves membrane disruption by growing IAPP fibrils (Engel et al. 2008) or by toxic hIAPP oligomers (Demuro et al. 2005; Engel 2009; Jayasinghe and Langen 2007; Kayed et al. 2003). It is well established that hIAPP is able to interact with membranes and that membranes can promote the aggregation of hIAPP (Knight and Miranker 2004; Janson et al. 1999; Sparr et al. 


\begin{tabular}{|c|c|}
\hline peptides & Sequences \\
\hline hLAPP $_{1-19}$ oxidized & KCNTATCATQRLANF LVHS- $\mathrm{NH}_{2}$ \\
\hline hLAPP $_{1-19}$ protected & $\begin{array}{l}\text { KÇNTATCATQRLANFLVHS- } \mathrm{NH}_{2} \\
\text { Me Me }\end{array}$ \\
\hline
\end{tabular}

Fig. 1 Amino acid sequences of oxidized and protected hIAPP ${ }_{1-19}$. Both peptides have an amidated C-terminus

2004). The initial step of membrane interaction of mature hIAPP is insertion of its N-terminus, most likely as the monomer (Engel et al. 2006). This N-terminus contains an evolutionary conserved disulfide bond between Cys2 and Cys7, presumably formed in the oxidizing environment of the endoplasmic reticulum. This disulfide bond has been shown to be essential for biological activity of hIAPP, i.e. its effect on insulin-stimulated glycogen synthesis (Roberts et al. 1989). Possibly related to this, an important role for the disulfide bridge was demonstrated in heparin binding (Abedini et al. 2006). With regard to its role in amyloid formation, it has been shown that the disulfide prohibits the $\mathrm{N}$-terminal region of hIAPP from adopting a $\beta$-sheet-rich structure (characteristic of amyloid fibrils) and that it is involved in amyloid formation in solution, albeit not as part of the core (Koo and Miranker 2005). However, to our knowledge no reports have yet been published on the possible role of the disulfide bond of hIAPP in membraneinteraction.

Because the disulfide bond is located in the N-terminal part of the peptide, and because the N-terminal part is primarily responsible for the interaction of hIAPP with membranes, we examined the effect of this disulfide on insertion of the peptide hIAPP $_{1-19}$ into membranes. In particular, we have examined the aggregational behavior, the membrane insertion, the secondary structure and the effect on lipid acyl chain order and on membrane leakage. For this purpose, we generated two hIAPP ${ }_{1-19}$ peptides (oxidized and protected hIAPP ${ }_{1-19}$, Fig. 1) and we investigated their interaction with model membranes composed of a mixture of the zwitterionic lipid phosphatidylcholine (POPC) and the anionic lipid phosphatidylserine (POPS) in a 7:3 ratio to mimic the membranes of pancreatic islet cells (Rustenbeck et al. 1994).

\section{Materials and methods}

\section{Materials}

1-Palmitoyl-2-oleoyl-sn-glycero-3-phosphocholine (POPC), 1-palmitoyl-2-oleoyl-sn-glycero-3-phospho-L-serine (POPS), and chain perdeuterated POPC and POPS (POPC- ${ }^{2} \mathrm{H}_{31}$ and POPS- ${ }^{2} \mathrm{H}_{31}$ ) were purchased from Avanti Polar Lipids (Alabaster, AL, USA).
Peptide synthesis and purification

The peptides (see Fig. 1 for the amino acid sequence) were synthesized using Fmoc chemistry on a Tentagel S RAM resin to provide an amidated C-terminus. Fmoc-Cys(Me)$\mathrm{OH}$ was used for the synthesis of the protected peptide; Fmoc-Cys(Trt)-OH was used for the synthesis of the linear peptide. Linear hIAPP ${ }_{1-19}$ was dissolved in aqueous DMSO and oxidized with air to the corresponding disulfide bond. All peptides were purified by HPLC using an Alltima $\mathrm{C}_{8}$ column $(100 \AA$ pore size, $10 \mu \mathrm{m}$ particle size, $25 \times 2.2 \mathrm{~cm}$ ). The peptides were eluted with a flow rate of $12.5 \mathrm{ml} / \mathrm{min}$. using a linear gradient of buffer $\mathrm{B}(100 \%$ in $100 \mathrm{~min})$ from $100 \%$ buffer $\mathrm{A}\left(0.1 \%\right.$ TFA in $\mathrm{CH}_{3} \mathrm{CN}-\mathrm{H}_{2} \mathrm{O}$ 5:95 v/v), buffer B $\left(0.1 \%\right.$ TFA in $\left.\mathrm{CH}_{3} \mathrm{CN}-\mathrm{H}_{2} \mathrm{O} 95: 5 v / v\right)$. Purity of the peptides was higher than $95 \%$ as determined by analytical HPLC, and the masses of the peptides were confirmed with MALDI-TOF mass spectrometry.

\section{Preparation of peptide samples}

Peptide stock solutions were prepared by dissolving the peptide at a concentration of $1 \mathrm{mM}$ in hexafluoroisopropanol (HFIP) and incubating for at least $1 \mathrm{~h}$. Next, HFIP was evaporated, followed by vacuum desiccation for $20 \mathrm{~min}$. The resulting peptide film was then dissolved to a final peptide concentration of $1 \mathrm{mM}$ in either DMSO for the monolayer or in an appropriate buffer containing the vesicles for the $\mathrm{CD}$ and the NMR experiments.

\section{Monolayer experiments}

Peptide-induced changes in the surface pressure of a monomolecular layer of phospholipids at constant surface area were measured with the Wilhelmy plate method, as reported previously (Engel et al. 2006). Surface pressures were measured at $22( \pm 2)^{\circ} \mathrm{C}$. Briefly, a Teflon trough was filled with $6.0 \mathrm{ml} 10 \mathrm{mM}$ Tris- $\mathrm{HCl}, 100 \mathrm{mM} \mathrm{NaCl}$ buffer (pH 7.4). Lipid monolayers were spread from a $1 \mathrm{mM}$ stock solution in chloroform, after which $10 \mu \mathrm{l}$ of a $600 \mu \mathrm{M}$ freshly prepared stock solution of the peptide was injected into the sub-phase. The final peptide concentration was $1 \mu \mathrm{M}$.

Preparation of LUVs (large unilamellar vesicles)

LUVs were prepared from POPC/POPS in a 7:3 molar ratio. Stock solutions of POPC and POPS in chloroform at concentrations of $20-30 \mathrm{mM}$ were mixed in a $7: 3$ molar ratio in a glass tube. The solvent was evaporated with dry nitrogen gas yielding a lipid film that was subsequently kept in a vacuum desiccator for 20 min. Lipid films were hydrated in $10 \mathrm{mM}$ phosphate buffer $(\mathrm{pH}$ 7.4) for at least 
$30 \mathrm{~min}$, at a lipid concentration of $10 \mathrm{mM}$. The lipid suspensions were subjected to ten freeze-thaw cycles, at temperatures of approximately -80 and $40^{\circ} \mathrm{C}$, and subsequently extruded ten times through $0.2 \mu \mathrm{m}$ pore-size filters (Anotop 10; Whatman, Maidstone, UK).

\section{CD spectroscopy}

CD spectra were acquired on a Jasco 810 spectropolarimeter (Jasco, Easton, MD, USA) over the wavelength range $190-270 \mathrm{~nm}$ at room temperature. Measurements were carried out in cells of $0.1 \mathrm{~mm}$ path length at room temperature in POPC/POPS (7:3) LUVs. Measurements were taken every $0.2 \mathrm{~nm}$ at a scan rate of $20 \mathrm{~nm} / \mathrm{min}$. Each spectrum reported is the average of five scans after subtraction of the baseline spectrum of the vesicles without peptide. Peptide concentrations were $50 \mu \mathrm{M}$ in the presence of lipids (peptide-to-lipid ratio 1:20). In order to estimate the peptide secondary structure content, analysis of relevant $\mathrm{CD}$ spectra was carried out using CDPro2 software (Sreerama and Woody 2000). The analysis was performed using the self-consistent method Contin-LL and the basis 10 that contains 56 reference proteins.

\section{Sample preparation for NMR experiments}

Mixtures of POPC and POPS (ratio 7:3) were co-dissolved in chloroform and evaporated under vacuum. The residual lipid film was hydrated in Tris- $\mathrm{HCl}, 100 \mathrm{mM} \mathrm{NaCl}$ buffer (pH 7.4). The solution was subjected to ten freeze-thaw cycles, at temperatures of approximately -80 and $40^{\circ} \mathrm{C}$, to homogenize the size of the MLV. For the samples containing the peptide, the lipid solution was added to the film of peptide at the beginning of the MLV preparation. A total lipid-to-peptide ratio of 20:1 was used.

\section{NMR experiments}

NMR experiments were carried out on a Bruker Advance $500 \mathrm{MHz}$ NMR spectrometer. ${ }^{2} \mathrm{H}$ NMR experiments on deuterated lipids were performed at $76.78 \mathrm{MHz}$ using a quadrupolar echo sequence. Typical acquisition conditions were: $2.5 \mu \mathrm{s} 90^{\circ}$ pulse, an echo delay of $50 \mu \mathrm{s}$, a recycling delay of $1.5 \mathrm{~s}, 500 \mathrm{kHz}$ spectral width, 4096 data points, 36000 scans. A line broadening of $100-200 \mathrm{~Hz}$ was applied prior to Fourier transformation. The temperature was regulated at $25 \pm 1{ }^{\circ} \mathrm{C}$. To gather information about effects of the peptides on local chain order, powder spectra were processed using the "de-Pake-ing" procedure, implemented by Bloom et al. (1981). The order parameters, $S_{\mathrm{CD}}$, were calculated by use of NMRFriend software (Buchoux et al. 2008).

\section{Results and discussion}

To evaluate the role of the disulfide bond in hIAPP ${ }_{1-19}$ on its membrane interactions, we synthesized two hIAPP ${ }_{1-19}$ peptides: an oxidized form and a protected form with a methyl group on each cysteine residue to avoid the formation of the disulfide bond during the experiments. The amino acid sequences of the peptides are shown in Fig. 1.

The oxidized peptide has a slightly higher tendency to insert than the protected peptide

To study the insertion of the peptides in lipid membranes, we performed monolayer experiments. Injection of a solution of either oxidized or protected hIAPP ${ }_{1-19}$ into the aqueous subphase below a POPC/POPS (7:3) monolayer resulted in a fast increase in the surface pressure after addition of each peptide. After $20 \mathrm{~min}$, at an initial surface pressure of $24 \mathrm{mN} / \mathrm{m}$, the increase in surface pressure induced by insertion of the oxidized hIAPP ${ }_{1-19}$ was $9.0 \pm 0.5 \mathrm{mN} / \mathrm{m}$, compared with an increase of $7.5 \pm 0.5 \mathrm{mN} / \mathrm{m}$ for the protected hIAPP ${ }_{1-19}$ (Fig. 2a), indicating efficient insertion for both peptides.

Next, we determined the maximal initial surface pressure at which the peptides were still able to insert, i.e. cause a further increase in surface pressure, by analysing the surface pressure increase as a function of initial surface pressure. The data from Fig. $2 b$ indicate that the extrapolated "limiting surface pressure" is high for all peptides and it seems to be slightly higher for the oxidized peptide $(47.2 \pm 0.7 \mathrm{mN} / \mathrm{m})$ than for the protected peptide $(44.7 \pm 0.8 \mathrm{mN} / \mathrm{m})$. In both cases, the limiting surface pressure is significantly higher than the surface pressures that correspond to the packing density in lipids in biological membranes, between 31 and $35 \mathrm{mN} / \mathrm{m}$ (Demel et al. 1975), indicating that in vivo also hIAPP ${ }_{1-19}$ can insert efficiently into membranes. The limiting surface pressure of hIAPP is of the same order, or even higher, than that of peptides with a known membrane activity, for example neuropeptides and antimicrobial peptides (Calvez et al. 2009). Thus, our results suggest that both peptides insert very efficiently into membranes, but that the oxidized peptide has a slightly higher capacity to insert than the protected peptide.

The oxidized peptide induces slightly more acyl chain disorder than the protected peptide

Next we investigated the effect of membrane insertion of these peptides on lipid chain order by ${ }^{2} \mathrm{H}$ NMR. The peptides were incorporated into bilayers of perdeuterated POPC/POPS at a 1:20 peptide-to-lipid molar ratio. ${ }^{31} \mathrm{P}$ NMR measurements confirmed that the lipids in these 

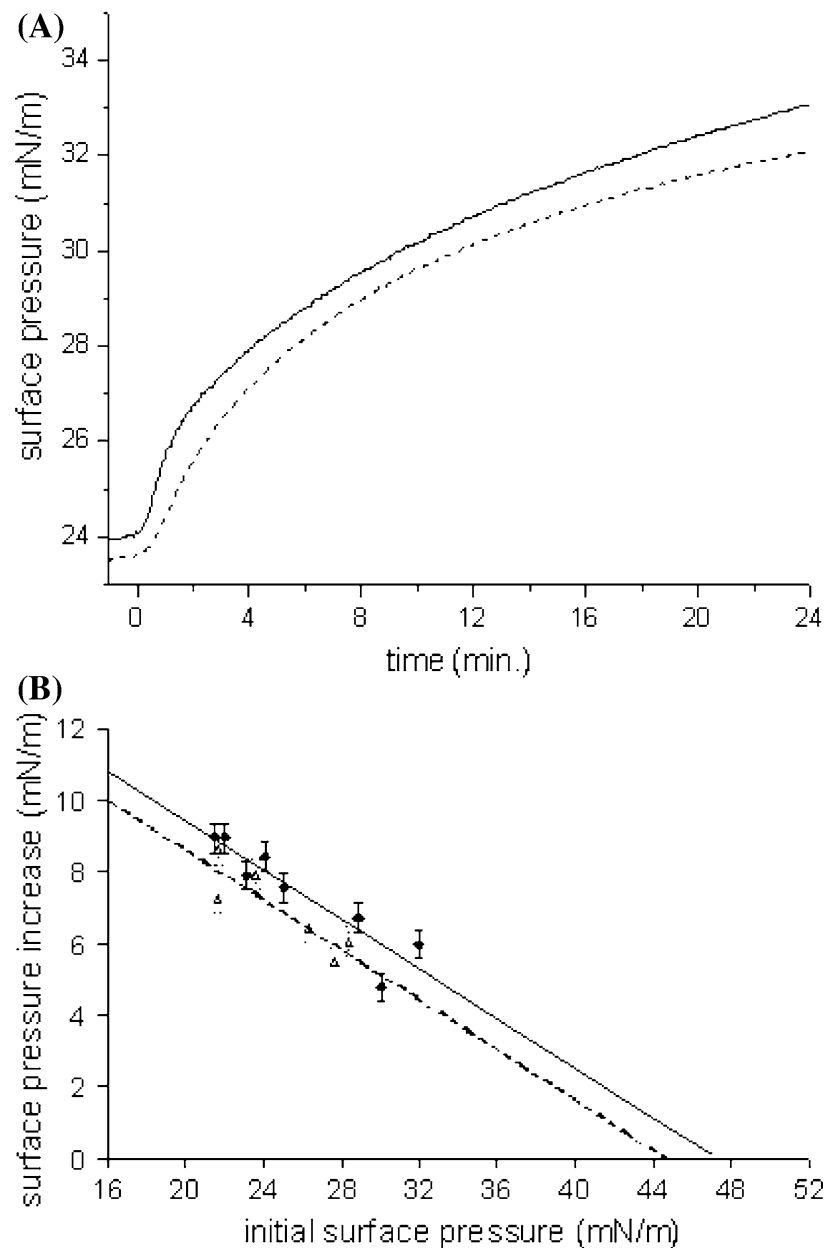

Fig. 2 a Surface pressure profile after injecting a sample of hIAPP $_{1-19}$ oxidized (solid line) and protected (dashed line) into a monolayer of POPC/POPS (7:3). The peptides were injected into the stirred sub-phase at $t=0 \mathrm{~min}$. The final peptide concentration was $1 \mu \mathrm{M}$. b Surface pressure increase induced by the interaction of freshly dissolved hIAPP ${ }_{1-19}$ oxidized (diamonds, solid line) and protected (triangles, dashed line) with POPC/POPS (7:3) monolayers as a function of the initial surface pressure. The final peptide concentration was $1 \mu \mathrm{M}$. The straight lines were obtained by linear regression. Experimental error is estimated at $\pm 0.5 \mathrm{mN} / \mathrm{m}$

systems are in a bilayer organization (data not shown). Figure 3a presents the ${ }^{2} \mathrm{H}$ NMR spectra of POPC- ${ }^{2} \mathrm{H}_{31} /$ POPS bilayer dispersions, with and without the peptides at $25^{\circ} \mathrm{C}$. In the case of $\mathrm{POPC}-{ }^{2} \mathrm{H}_{31} / \mathrm{POPS}$, we observe the typical behavior of this system, characteristic of a lamellar fluid phase (Salnikov et al. 2009). The spectra exhibit many resolved splittings. The smallest splitting, corresponding to the methyl groups at the end of the acyl chains, is about $5.0 \mathrm{kHz}$ and the largest, corresponding to the $\mathrm{CD}_{2}$ groups closest to the glycerol backbone, is approximately $25.9 \mathrm{kHz}$. In the presence of the peptides, no characteristic changes in spectrum shape occur. Thus, addition of the oxidized peptide or the protected peptide does not induce a global perturbation of the dynamics of the membrane
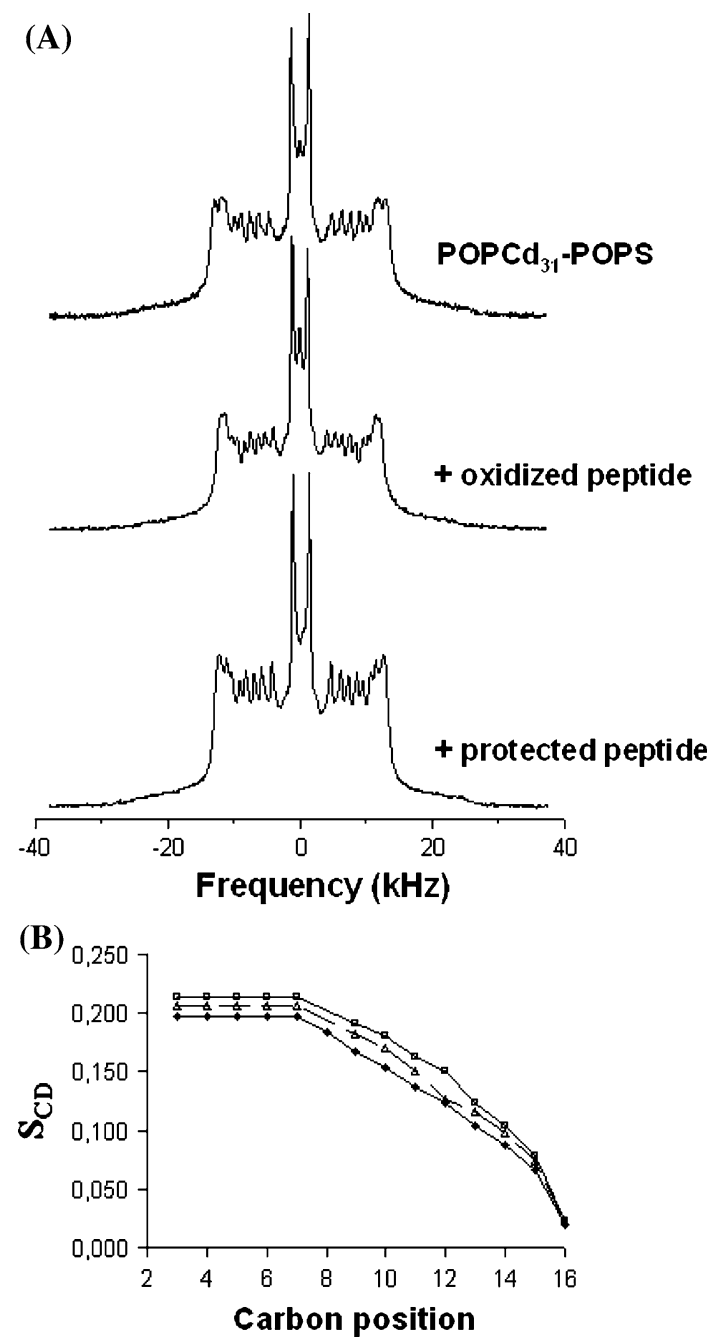

Fig. 3 a ${ }^{2} \mathrm{H}$ NMR spectra for peptides/POPC- $d_{31} / \mathrm{POPS}$ dispersions at a 1:20 molar ratio and at $25^{\circ} \mathrm{C}$. Spectra are shown without peptide and for samples containing the peptides indicated. b $S_{\mathrm{CD}}$ profile without peptide (squares), with $\mathrm{hIAPP}_{1-19}$ oxidized (diamonds) and protected (triangles) calculated for de-Paked spectra at $25^{\circ} \mathrm{C}$. Carbon position 16 represents the end of the chain. Experimental error is in symbol size

matrix. However, the width of the spectra seems slightly reduced, with the largest splitting now being $24.9 \mathrm{kHz}$ for the protected peptide and $24.1 \mathrm{kHz}$ for the oxidized peptide. Figure $3 \mathrm{~b}$ shows the profile of the order parameter $\left(S_{\mathrm{CD}}\right)$ for each carbon position in the lipid chain in the presence and in the absence of peptide. The POPC- ${ }^{2} \mathrm{H}_{31}$ chain order is lower when either peptide is present in the system. This is particularly true for the "plateau" positions (carbons 2 to 6). Toward the chain end (positions 15 and 16) the effect is less marked or absent. In addition, our results show that the POPC- ${ }^{2} \mathrm{H}_{31}$ chain order is lower with the oxidized peptide than with the protected one. The ${ }^{2} \mathrm{H}$ NMR spectra of POPC/POPS- ${ }^{2} \mathrm{H}_{31}$ bilayer dispersions were also recorded. The same effect as for the POPC- ${ }^{2} \mathrm{H}_{31} /$ 
POPS bilayer was observed. The membrane-disorder induced by hIAPP is of the same order as that of peptides with a known membrane activity, for example antimicrobial peptides (Salnikov et al. 2009; Balla et al. 2004). In addition, it was recently shown that $\mathrm{A} \beta 42$, the peptide that forms amyloid fibrils in Alzheimer's disease, also induced membrane disorder in POPC/POPS bilayers (Gehman et al. 2008; Lau et al. 2006). This result can be correlated with that of the monolayer study: the oxidized peptide inserts better and induces more disorder into the membrane than the protected peptide, suggesting that the disulfide bond somewhat affects the mode of membrane insertion of hIAPP $_{1-19}$.

The oxidized peptide has slightly less $\alpha$-helical structure than the protected peptide in the presence of membranes

The small differences in mode of insertion of the oxidized and protected peptide may be because of differences in conformation. We therefore used CD spectroscopy to determine whether the disulfide bridge affects the membrane-bound secondary structure of the peptide in the presence of POPC/POPS membranes. A previous study showed that oxidized hIAPP ${ }_{1-19}$ adopts $\alpha$-helical structure upon addition of POPG liposomes (Brender et al. 2008). Consistent with this, our CD spectra in POPC/POPS (7:3) of the oxidized peptide display negative ellipticity at 208 and $222 \mathrm{~nm}$, characteristic of $\alpha$-helical backbone structure (Fig. 4). A similar spectrum is observed for the protected peptide. However, the minimum of the protected peptide is slightly more intense than the minimum of the oxidized peptide. This suggests that the protected peptide has a slightly larger $\alpha$-helical content than the oxidized peptide.

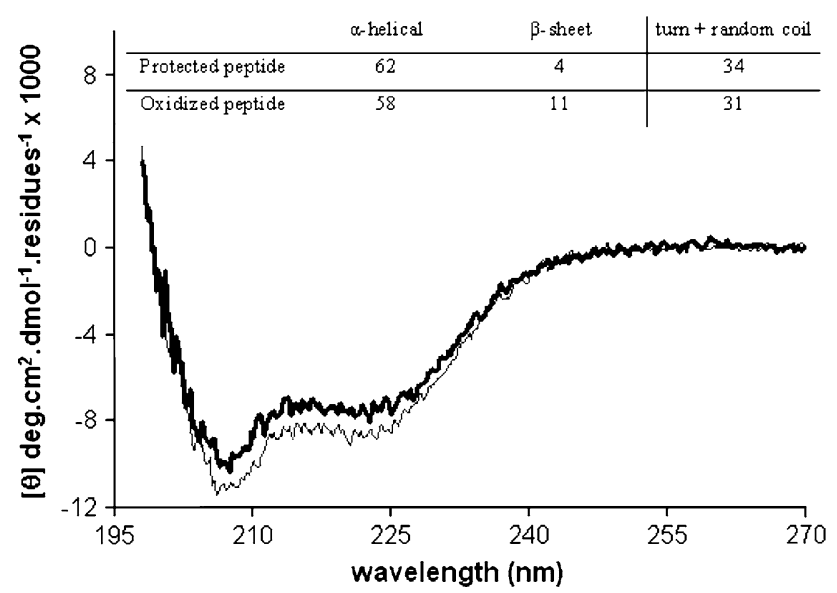

Fig. $4 \mathrm{CD}$ spectra of $50 \mu \mathrm{M}$ hIAPP $_{1-19}$ oxidized (bold line) and protected (thin line) in the presence of POPC/POPS 7:3 LUVs (peptide-to-lipid ratio 1:20). The inset shows the deconvolution of $\mathrm{CD}$ spectra of the peptides
This is supported by deconvolution of CD traces, where $62 \% \alpha$-helical contribution is obtained for the protected peptide and $58 \% \alpha$-helical for the oxidized peptide (inset of Fig. 4). This result suggests that in the presence of membranes the disulfide bond only slightly affects the secondary structure of hIAPP $1-19$.

The disulfide bond does not influence the effect of hIAPP $_{1-19}$ on membrane barrier properties or its inability to form amyloid fibers

We wanted to know if the disulfide has an effect on membrane damage and fibril formation. Membrane damage was assayed quantitatively by analyzing the extent of leakage of a fluorescent dye (calcein) from LUVs. The results demonstrate that neither peptide is able to induce significant membrane damage (leakage $<5 \%$, data not shown), despite their ability to efficiently insert into a lipid monolayer and to induce slight bilayer disorder. Also, under these conditions, i.e. in the presence of POPC/POPS LUVs, neither peptide forms fibrils as determined by transmission electron microscopy and thioflavin $\mathrm{T}$ fluorescence, even after 15 days of incubation (data not shown). These findings are in agreement with our previous work, which indicated that fibril growth is a requirement for amyloid-induced membrane damage (Engel et al. 2008).

\section{Conclusion}

Our results suggest that the presence of the disulfide bond has only small effects on membrane interaction of hIAPP. Its removal in hIAPP $_{1-19}$ results in a slight decrease in membrane insertion, a decrease in the effect of the peptide on membrane disorder, and a small increase in $\alpha$-helical structure. The inability of $\mathrm{hIAPP}_{1-19}$ to induce membrane damage and to form fibrils in the presence of membranes is not changed upon removing the disulfide bond.

Based on the results presented here, and on our previous results (Engel et al. 2006), we conclude that the N-terminal residues of IAPP are important for membrane insertion, but that the disulfide linked residues 2-7 seem much less responsible than the other residues (8-19) for this interaction. This notion is in agreement with two recent studies, which indicate that residues 9 to 22 of hIAPP form a helix that binds to phospholipid bilayers (Apostolidou et al. 2008; Nanga et al. 2009) whereas residues 1 to 8 , containing the disulfide, do not interact directly with the membrane. Thus, the fact that the cysteines are evolutionarily conserved is most likely related exclusively to the biological activity of IAPP as a hormone, where these cysteines may be involved in interactions with other cellular components than lipids, e.g. with an IAPP receptor. 
Acknowledgments This research was financially supported by the European Commission through a Marie Curie Post-doctoral fellowship. We thank Annemarie Dechesne and Hans Jacobs for performing mass spectrometry analysis, Ronald Elgersma for HPLC advice, Jacques Doux for NMR advice, and Gemma Lahoz Casarramona for helpful discussions.

Open Access This article is distributed under the terms of the Creative Commons Attribution Noncommercial License which permits any noncommercial use, distribution, and reproduction in any medium, provided the original author(s) and source are credited.

\section{References}

Abedini A, Tracz SM, Cho JH, Raleigh DP (2006) Characterization of the heparin binding site in the N-terminus of human pro-islet amyloid polypeptide: implications for amyloid formation. Biochemistry 45:9228-9237

Akesson B, Panagiotidis G, Westermark P, Lundquist I (2003) Islet amyloid polypeptide inhibits glucagon release and exerts a dual action on insulin release from isolated islets. Regul Pept 111:55-60

Apostolidou M, Jayasinghe SA, Langen R (2008) Structure of alphahelical membrane-bound human islet amyloid polypeptide and its implications for membrane-mediated misfolding. J Biol Chem 283:17205-17210

Balla MS, Bowie JH, Separovic F (2004) Solid-state NMR study of antimicrobial peptides from Australian frogs in phospholipid membranes. Eur Biophys J 33:109-116

Bloom M, Davis JH, Mackay AL (1981) Direct determination of the oriented sample NMR spectrum from the powder spectrum for systems with a local axial symmetry. Chem Phys Lett 80:198-202

Brender JR, Lee EL, Cavitt MA, Gafni A, Steel DG, Ramamoorthy A (2008) Amyloid fiber formation and membrane disruption are separate processes localized in two distinct regions of IAPP, the type-2-diabetes-related peptide. J Am Chem Soc 130:6424-6429

Buchoux S, Lai-Kee-Him J, Garnier M, Tsan P, Besson F, Brisson A, Dufourc EJ (2008) Surfactin-triggered small vesicle formation of negatively charged membranes: a novel membrane-lysis mechanism. Biophys J 95:3840-3849

Calvez P, Bussieres S, Eric D, Salesse C (2009) Parameters modulating the maximum insertion pressure of proteins and peptides in lipid monolayers. Biochimie 91:718-733

Demel RA, Geurts van Kessel WS, Zwaal RF, Roelofsen B, van Deenen LL (1975) Relation between various phospholipase actions on human red cell membranes and the interfacial phospholipid pressure in monolayers. Biochim Biophys Acta 406:97-107

Demuro A, Mina E, Kayed R, Milton SC, Parker I, Glabe CG (2005) Calcium dysregulation and membrane disruption as a ubiquitous neurotoxic mechanism of soluble amyloid oligomers. J Biol Chem 280:17294-17300

Engel MFM (2009) Membrane permeabilization by islet amyloid polypeptide. Chem Phys Lipids 160:1-10

Engel MFM, Yigittop H, Elgersma RC, Rijkers DT, Liskamp RM, de Kruijff B, Höppener JW, Killian JA (2006) Islet amyloid polypeptide inserts into phospholipid monolayers as monomer. J Mol Biol 356:783-789

Engel MFM, Khemtémourian L, Kleijer CC, Meeldijk HJ, Jacobs J, Verkleij AJ, de Kruijff B, Killian JA, Höppener JW (2008) Membrane damage by human islet amyloid polypeptide through fibril growth at the membrane. Proc Natl Acad Sci USA 105:6033-6038

Gehman JD, O'Biren CC, Shabanpoor F, Wade JD, Separovic F (2008) Metal effects on the membrane interactions of amyloid- $\beta$ peptides. Eur Biophys J 37:333-344

Höppener JW, Ahren B, Lips CJ (2000) Islet amyloid and type 2 diabetes mellitus. N Engl J Med 343:411-419

Janson J, Ashley RH, Harrison D, McIntyre S, Butler PC (1999) The mechanism of islet amyloid polypeptide toxicity is membrane disruption by intermediate-sized toxic amyloid particles. Diabetes 48:491-498

Jayasinghe SA, Langen R (2007) Membrane interaction of islet amyloid polypeptide. Biochim Biophys Acta 1768:2002-2009

Kayed R, Head E, Thompson JL, McIntire TM, Milton SC, Cotman CW, Glabe CG (2003) Common structure of soluble amyloid oligomers implies common mechanism of pathogenesis. Science 300:486-489

Khemtémourian L, Killian JA, Höppener JW, Engel MFM (2008) Recent insights in islet amyloid polypeptide-induced membrane disruption and its role in beta-cell death in type 2 diabetes mellitus. Exp Diabetes Res 2008:421287

Knight JD, Miranker AD (2004) Phospholipid catalysis of diabetic amyloid assembly. J Mol Biol 341:1175-1187

Koo BW, Miranker AD (2005) Contribution of the intrinsic disulfide to the assembly mechanism of islet amyloid. Prot Sci 14:231-239

Lau TL, Ambroggio EE, Tew DJ, Cappai R, Masters CL, Fidelio GD, Barnham KJ, Separovic F (2006) Amyloid- $\beta$ peptide disruption of lipid membranes and the effect of metal ions. J Mol Biol 356:759-770

Nanga RP, Brender JR, Xu J, Hartman K, Subramanian V, Ramamoorthy A (2009) Three-dimensional structure and orientation of rat islet amyloid polypeptide protein in a membrane environment by solution NMR spectroscopy. J Am Chem Soc 131:8252-8261

Reda TK, Geliebter A, Pi-Sunyer FX (2002) Amylin, food intake, and obesity. Obes Res 10:1087-1091

Roberts AN, Leighton B, Todd JA, Cockburn D, Schofield PN, Sutton R, Holt S, Boyd Y, Day AJ, Foot EA, Willis AC, Reid KBM, Cooper GJS (1989) Molecular and functional-characterization of amylin, a peptide associated with type-2 diabetes-mellitus. Proc Natl Acad Sci USA 86:9662-9666

Rushing PA, Hagan MM, Seeley RJ, Lutz TA, D’Alessio DA, Air EL, Woods SC (2001) Inhibition of central amylin signaling increases food intake and body adiposity in rats. Endocrinology 142:5035

Rustenbeck I, Matthies A, Lenzen S (1994) Lipid composition of glucose-stimulated pancreatic islets and insulin-secreting tumor cells. Lipids 29:685-692

Salnikov ES, Mason AJ, Bechinger B (2009) Membrane order perturbation in the presence of antimicrobial peptides by (2) $\mathrm{H}$ solid-state NMR spectroscopy. Biochimie 91:734-743

Sparr E, Engel MFM, Sakharov DV, Sprong M, Jacobs J, de Kruijff B, Höppener JWM, Killian JA (2004) Islet amyloid polypeptideinduced membrane leakage involves uptake of lipids by forming amyloid fibers. FEBS Lett 577:117-120

Sreerama N, Woody RW (2000) Estimation of protein secondary structure from circular dichroism spectra: comparison of CONTIN, SELCON, and CDSSTR methods with an expanded reference set. Anal Biochem 287:252-260

Westermark P, Wilander E, Westermark GT, Johnson KH (1987) Islet amyloid polypeptide-like immunoreactivity in the islet B cells of type 2 (non-insulin-dependent) diabetic and non-diabetic individuals. Diabetologia 30:887-892 